\title{
Construction of the Training Mode of the Combination of Clinical Medical Professional Degree Graduate Education and Resident Standardized Training
}

\author{
Jinjun $\mathrm{Li}^{1 *}$, Qingming $\mathrm{Wu}^{1}{ }^{*}$, Ting $\mathrm{Yu}^{1}$, Yi Zou${ }^{2}$, Yunjie $\mathbf{L i}^{2}$ \\ ${ }^{1}$ Medical College, Wuhan University of Science and Technology, Wuhan, China \\ ${ }^{2}$ Xiaogan Central Hospital Affiliated to Wuhan University of Science and Technology, Wuhan, China \\ Email: "entry2003@126.com, "wuhe9224@sina.com
}

Received 31 January 2016; accepted 6 May 2016; published 9 May 2016

Copyright (C 2016 by authors and Scientific Research Publishing Inc.

This work is licensed under the Creative Commons Attribution International License (CC BY).

http://creativecommons.org/licenses/by/4.0/

\section{(c) (i) Open Access}

\begin{abstract}
Beginning in 2014 as a major education reform in China, the implementation of clinical medicine specialized graduate student training combined with standardized resident training system as well as Chinese clinical medical professional degree system binding with the standardized training of residents becomes the highlight and difficulty of this medical educational reform. Through optimizing clinical medical professional degree graduate training scheme and innovative teaching mode and improving the management system, the specialized degree graduate students will be trained to be truly "Qualified doctor "and high-level applied talents.
\end{abstract}

\section{Keywords}

Postgraduate Education, Reform in Education, Clinical Medicine Professional Degree, Resident Standardized Training

\section{Introduction}

The combination of training of graduate students in clinical medicine and standardized training of resident doctors is an important measure for the reform of Chinese Medical Science degree system and postgraduate educa-

${ }^{*}$ Corresponding authors.

How to cite this paper: Li, J. J., Wu, Q. M., Yu, T., Zou, Y., \& Li, Y. J. (2016). Construction of the Training Mode of the Combination of Clinical Medical Professional Degree Graduate Education and Resident Standardized Training. Creative Education, 7, 802-806. http://dx.doi.org/10.4236/ce.2016.76082 
tion. How to do the professional degree education and industry certification of organic convergence to ensure the quality of training is a major issue with which the professional degree graduate education is faced. Combined with our own culture in clinical medicine research degree students and hospital standardized training of residents work in reality, to construct to foster truly "Qualified doctor" as the goal, graduate students truly become the high-level applied talents (Science and Technology Education Department, 2013). The combination of training of graduate students and standardized training of resident doctors is an important measure for the reform of medical education reform in our country (Science and Technology Education Department, 2014; Ministry of Education of the People's Republic of China, 2014). This new type of training mode is mainly to cultivate both good clinical practice ability, but also has a certain degree of clinical scientific research ability of high-level medical talents, The professional degree of clinical medicine professional degree graduate training process and resident standardized training of organic combination, professional degree education and professional certification of organic convergence. And it ensures the quality of clinical medicine professional degree graduate training, and can effectively save education and training resources and improve the efficiency of personnel training, professional degree graduate education to solve the problem of qualification certification. Postgraduate education is the highest level of China's higher education. Constantly improving the quality of graduate education is the key to enhance the core competitiveness of our country.

\section{Methods}

\subsection{Optimization of the Training Program for the Graduate Students of Clinical Medicine}

Objectives of the Training Program for Clinical Medical Professional Degree Graduate

The purpose of the training program is to reflect the characteristics of the professional, nurture the quality; comprehensive, professional solid theory, specialized knowledge system, specialist skilled, with prominent clinical analysis and thinking ability and strong clinical scientific research ability, to lead the progress of medical technology of high level, high-quality clinicians. The content of medical curricula and postgraduate specialist training programmes should continuously reflect the changes in society (Borleffs, 2013). To formulate the training plan, namely, combination of the clinical medicine professional master's degree and the standardized training of resident doctors according to the goal of "humanistic quality, professional knowledge and clinical competence". The curriculum system is not only in line with the training objectives of clinical medical professional degree, but also can meet the requirements of the standardized training of resident doctors.

1) To correctly grasp the training aim of master degree in clinical medicine. The high-level applied talents need to master a solid basic theory and system of specialized knowledge in clinical medicine, and have the ability to engage in clinical medical science research work or independently take on specialized technical work.

2) Through the clinical doctor practicing qualification examination, and the resident standard training and the specialized training. To fully agree with the core requirements of the education and training program for excellent physicians: to strengthen the professional ethics education, to strengthen the training of clinical practice ability.

3) The training program is focused on the course of study and clinical practice (standardized training of residents and the sub specialty training), reflecting the "solid foundation, strengthen skills, promote the expertise" of the basic characteristics.

\subsection{The Guiding Ideology of the Standardized Training Course System for the Graduate Students of Clinical Medicine Specialty}

Combined with clinical medical professional degree graduate students training and hospitalization requirements of the standardized training of residents in the curriculum system of graduate curriculum, guiding ideology is: changing traditional ideas, strengthening interdisciplinary, integrating the advantages of disciplines, in accordance with hospital requirements of the standardized training of residents in the formulation. Setting up a high level, high depth and breadth of the graduate education curriculum system and actively building a platform for public courses and quality courses. Setting up clinical thinking analysis, clinical communication and so on, having the characteristics of medical humanities quality courses, as well as cross disciplinary and interdisciplinary courses, the training of graduate students' clinical ability 


\section{Innovative Teaching Mode, Pay Attention to the Combination of Clinical Medicine Master's Degree in Postgraduate Education and Standardized Training for Residents}

1) Master of clinical professional degree graduate education is a degree education; the main goal of training is to have a strong clinical diagnosis and clinical research ability, good practice quality of the application of medical professionals. The standardized training of resident physicians is launched after graduation education, and to cultivate rich clinical experience with strong clinical thinking and special clinical practice basic skills, this medical education includes two different types and phases. To explore and innovate better training mode, it can efficiently integrate two kinds of training objectives, and in consideration of two kinds of different training places and training excellent ability of clinical practice, the patients of high-level medical talents has become an important issue in the field of higher medical education.

2) To construct integrated curriculum system of clinical medical professional master's degree and the standardized training of resident doctors. The curriculum requires graduate students to change traditional concept, and strengthen interdisciplinary training integrating the advantages of subject in accordance with the requirements of standardized training of resident doctors. To set up clinical analytical thinking, effective clinical communication and so on, have a good command of characteristics of medical humanities quality courses, as well as cross disciplinary and interdisciplinary courses, thus, the improving the graduate students' clinical ability.

3) To strengthen the training of clinical practice and standardized residency training. According to the length of the standardized residency training, the standardized training should be integrated into clinical related specialty cycle. Clinical rotation includes no less than 6 of clinical disciplines in third grade. The training time is supposed to be not less than 6 months under three level of the tutor.

4) To advocate students to incorporate clinical practice topics, including treatment scheme design of clinical cases summary, analysis of difficult medical record, clinical data and other aspects of research, foster graduate training on clinical issues and analytical thinking ability. The relevant courses are offered as follows: clinical research design and scientific research writing, evidence-based medicine, clinical thinking training and application, doctor-patient communication skills and applications, advances in clinical medicine, internal medicine, surgery, etc.

\section{Attach Importance to the Cultivation of Clinical Ability of Graduate Students}

1) Focus on the clinical ability training of graduate students. According to the training program, departments and instructors should develop a round of planning, designate responsible person on the subject in charge of teaching and management on the basis of training needs of rotary professional basic disciplines, disciplines and cross discipline. Clinical medical professional degree graduate have to participate in full departments' rotation such as discipline ward, outpatient and emergency departments in order to master the subject of common disease and the pathogenesis of multiple history collection and writing, diagnosis, differential diagnosis, treatment method and basic operation along with clinical work to learn the relevant knowledge. At the same time, the quantitative indicators of clinical competence training can be clearly defined, and standardized training program of resident doctors strictly abide by the training program.

a) Clinical ability training is the key and basic link of clinical medical professional degree graduate education. Senior physician, as graduate' teachers, will guide graduate to collect medical history, physical examination, reading, form analysis of inspection report, diagnosis and medical record writing, the use of professional lectures, teaching rounds, case discussion, surgical operation and demonstration, graduate students in charge, and systematic, standardized clinical comprehensive ability training.

b) In order to ensure the quality of assessment, relevant evaluation system and standards should be established and improved, the clinical skills assessment should be divided into examination and evaluation stage and graduation examination, theory test and practice. Stage progressive training and evaluation scheme should be developed, including examination, annual assessment, mid-term examination, clinical skill examination, clinical skills graduation examination.

2) Cultivation of clinical research ability of graduate students. It is attached great importance to the cultivation of clinical training of scientific research ability and degree of scientific research ability according to the requirements throughout the whole process of training.

a) Clinical training of scientific research ability include literature review learning, summary writing, topic se- 
lection and design, experimental methods and data accumulation, sorting and statistical processing, paper writing, cultivation of scientific thinking, mastering related research work. Tutors of postgraduates' scientific research should pay attention to development of students' subjective initiative, independently choosing scientific subjects by students themselves, completion of clinical experience summary, forming a new view of disease diagnosis, treatment and pathogenesis, or improving clinical medical technology, a new method combined with clinical work.

b) Choosing thesis topic of the professional degree graduate student is required to combine the characteristic of superiority in clinical department, solving the clinical practice questions. The source of the subject is wide and varied, involving the etiology, diagnosis, treatment and prognosis of clinical common and multiple diseases, including clinical research, experience summary, follow-up study, experimental study and so on. Graduate students should cultivate the ability to analyze and solve problems in terms of scientific research and training at the same time, participating in academic conferences, academic forum, broadening the vision of academic field as well as research ideas, thus, stimulating innovation potential. In order to guarantee the quality of the thesis, famous experts should often be invited to hold scientific research lectures.

3) Training for graduate students' humanities ability and communication skills. Qualified medical professionals for modern society need to be well informed with medical knowledge as well as humanistic knowledge such as ethic morals, abilities and skills to communicate with patients. Under the guidance of instructors, medical graduate students in clinical probation teaching and practice have to attend teaching rounds, case discussion, talk to the patient and psychological counseling to improve their ability to communicate.

\section{Strengthening the Management of the Training Quality of the Graduate Students of Clinical Specialty}

To enhance quality management of postgraduate medical training, the faculty around the clinical medical professional degree graduate training needs to formulate clinical ability evaluation system and clinical training tutorial system, thus strengthening the clinical medical professional degree graduate quality management work. Affiliated hospital also need to develop professional degree graduate management regulations accordingly, reasonable arrangements for clinical education resources, so as to ensure to meet the basic needs of professional degree graduate training, providing the instructor for professional degree postgraduate clinical training to ensure implementation of graduate student clinical rotations. Clinical departments, according to their own characteristics, have to formulate the graduate management rules, and establishment of departmental rotation examination for graduate students, develop the professional degree graduate clinical rotation program such as departmental rotation examination, the clinical rotations and departmental rotation standardized examination. The teaching management and training quality of graduate students need to be further explored and improved in order to make the training more reasonable and scientific (Slootweg, Scherpbier, \& Leeuw, 2015).

\section{Discussion}

There are two kinds of medical education mode in our country at present. One is the standardized training for resident doctors, and the other is the cultivation of clinical professional degree. Standardized training is the object of medical college graduates. The purpose is to make the training of undergraduate students through the two phase of the system of clinical training, so that qualified clinicians grow (Science and Technology Education Department, 2014; Ministry of Education of the People's Republic of China, 2014). With the development of modern medicine, the traditional concept of medical education has been gradually replaced by the modern education concept. In most countries of the world, the concept of medical education includes three stages: basic education, medical education after graduation and continuing medical education. Although the properties of three stages are different, they are interrelated, and play a vital role of connection between the preceding and the following in cultivation of high-level, high-quality medical talents (Noormahomed, Mocumbi, \& Preziosi, 2013). Referring to foreign residency training mode (Buchanan, Jelsma, \& Siegfried, 2015; Salajegheh, Jahangiri, \& Evans, 2016), the content of medical curricula and postgraduate specialist training programmes should continuously reflect the changes in society (Borleffs, 2013). China's medical and health departments have been aware of the importance of training medical talents standard; in the training of medical personnel, in addition to improve the students' clinical research ability, innovation ability, accomplishment of medical theory, clinical communication ability and humanistic literacy outside, should pay attention to the training of clinical compe- 
tence.

The main objective of the clinical professional degree graduate education is to cultivate the high level application professionals to meet the needs of our country's medical career. Professional degree of clinical medicine graduate education and resident standardized training are in the exploratory stage. We have taken various measures to explore the clinical medicine professional degree graduate education and residency standardized training, and provided a new idea for the convergence of professional degree graduate education and professional qualification certification.

\section{References}

Borleffs, J. C. (2013). Medicaleducation: Future-Proof? Perspectives on Medical Education, 2, 1-3. http://dx.doi.org/10.1007/s40037-013-0040-9

Buchanan, H., Jelsma, J., \& Siegfried, N. (2015). Measuring Evidence-Based Practice Knowledge and Skills in Occupational Therapy-A Brief Instrument. Buchanan et al. BMC Medical Education, 15, 191. http://dx.doi.org/10.1186/s12909-015-0475-2

Ministry of Education of the People's Republic of China (2014). The Opinions of the Six Departments of the Ministry of Education on the Reform of Medical Education Cooperation and Deepening the Reform of Clinical Medical Personnel Training. http://www.moe.edu.cn/publicfiles/business/htmlfiles/moe/s7065/201411/178832.html

Noormahomed, E. V., Mocumbi, A. O., \& Preziosi, M. et al. (2013). Strengthening Research Capacity through the Medical Education Partnership Initiative: The Mozambique Experience. Human Resources for Health, 11, 62.

http://dx.doi.org/10.1186/1478-4491-11-62

Salajegheh, A., Jahangiri, A., \& Evans, E. D. et al. (2016). A Combination of Traditional Learning and E-Learning Can Be More Effective on Radiological Interpretation Skills in Medical Students: A Pre- and Post-Intervention Study. BMC Medical Education, 16, 46. http://dx.doi.org/10.1186/s12909-016-0569-5

Science and Technology Education Department (2013). Guidance on the Establishment of Standardized Training System for Resident Doctors. National Health and Family Planning Commission of the PRC. http://www.nhfpc.gov.cn/qiiys/s3593/201401/032c8cdf2eb64a369cca4f9b76e8b059.shtml

Science and Technology Education Department (2014). Standardized Training Content and Standard of Resident Doctors (for Trial Implementation). National Health and Family Planning Commission of the PRC. http://www.nhfpc.gov.cn/qjjys/s3593/201411/fd019826ce734430b3ea91edff5e6cb7.shtml

Slootweg, I. A., Scherpbier, A., \& Leeuw, R. et al. (2015). Team Communication amongst Clinical Teachers in a Formal Meeting of Post Graduate Medical Training. Advances in Health Sciences Education, 21, 207-219.

http://dx.doi.org/10.1007/s10459-015-9627-8 